\title{
PERFIL DA MORTALIDADE NA CIDADE DE CRICIÚMA (SC), NO PERÍODO DE 2005 A 2014
}

\begin{abstract}
Lucas Corrêa Preis
Acadêmico do Curso de Enfermagem, Centro Universitário Barriga Verde,

lucaspreis@yahoo.com

Greice Lessa

Doutoranda em Enfermagem, Universidade Federal de Santa Catarina, greicelessa@hotmail.com
\end{abstract}

\section{RESUMO}

O perfil das mortalidades brasileiras e mundiais vem mudando ao longo dos últimos anos, trazendo consigo elevados índices de mortes por doenças crônicas e não transmissíveis (DCNT) e deixando para trás os elevados índices de óbitos em razão das doenças decorrentes de causas infecciosas e parasitárias, em função da urbanização rápida das cidades e do desenvolvimento dos países. Atualmente, as causas de mortes são conhecidas por meio dos registros médicos nas declaraçôes de óbitos e que, posteriormente, são inseridas no sistema de informação de mortalidade, lançado pelo Ministério da Saúde, com o objetivo de compilar todas as informaçóes das mortes ocorridas em território nacional (CAMPOS; CERQUEIRA; NETO, 2011). Dessa forma, o trabalho objetiva apresentar o perfil de mortalidade do município de Criciúma (SC), com base nos dados disponíveis nos sistemas de informação, descrevendo as principais causas que representaram o maior índice de mortes entre o período analisado. Essa pesquisa é um estudo descritivo, retrospectivo e náo probabilístico, realizada com dados secundários obtidos nos sistemas de informação on-line, da Diretoria de 
Vigilância Epidemiológica do Estado de Santa Catarina. Os dados foram localizados no site da instituição, no Sistema TABNET, no item mortalidade, no período de 2005 a 2014, utilizando todas as causas de morte. Destaca-se que os dados são de domínio público, com acesso disponível pela rede mundial de computadores. Foi selecionado intencionalmente o município de Criciúma, localizado no sul de Santa Catarina, com uma populaçáo de 192.308 habitantes (IBGE, 2010). Foram coletados dados do sistema informatizado TABNET, no período de 04 a 22 de janeiro de 2016, relativos às seguintes variáveis: cidade de residência, ano e mês do óbito, sexo, faixa etária, escolaridade, estado civil e causa da morte. Os dados foram consolidados em uma planilha do programa Excel, versão 2010. A partir da coleta de dados, chegou-se a 10.271 mortes entre os anos de 2005 a 2014, no município de Criciúma, sendo que os anos de 2011, 2012 e 2013 representaram a maior quantidade de mortes, com 1.114, 1.143 e 1.125 óbitos, respectivamente. A prevalência de mortes foi da populaçáo do sexo masculino, com 5.832 óbitos, seguida da população do sexo feminino, 4.438 mortes. Além disso, um caso de morte foi registrado, cujo sexo foi declarado como ignorado no sistema. Em relação à faixa etária, a prevalência se deu em indivíduos com idade entre 70 e 79 anos, representando 2.107 óbitos, seguida da população idosa de 80 anos e mais, com 2.096 casos. A menor incidência se deu em crianças cuja idade estava entre 5 e 9 anos, com 33 casos de mortes no período. No que diz respeito à escolaridade da população que veio a óbito, entre o período analisado, a maior prevalência se deu em indivíduos com 4 a 7 anos de estudo, representando 3.307 óbitos no período. Já a menor incidência se deu na populaçáo com 12 anos ou mais de estudos, representando 435 casos de óbitos do total. Aproximadamente, $50 \%$ da população que veio a óbito, no período analisado, era casada, com 4.439 casos, seguida da população viúva, com 2.651. A populaçáo cujo estado civil era solteiro representou o terceiro maior índice, com 1.734 casos de mortes. Quanto às causas de óbitos, as que mais se destacaram no período e na cidade estudada foram às doenças do aparelho circulatório (com 3.581 óbitos), as neoplasias (com 2.003 óbitos), as doenças do aparelho respiratório (com 1.069 óbitos), as causas externas de morbidade e mortalidade (com 1.046 óbitos) e as doenças infecciosas e parasitárias (com 
551 óbitos). O perfil das mortalidades brasileiras, no ano de 1930, mostrava-se elevado para as doenças infecciosas e parasitárias, representando $46 \%$ do total de mortes nas capitais, passando para aproximadamente 5\% no ano de 2003. Atualmente, as DCNT são as responsáveis pelos maiores índices de mortes no Brasil, o que representa um grave problema a ser enfrentado pelos serviços de saúde, em função dos elevados índices de mortes por estas causas. Estima-se que, em 2010, as DCNT foram responsáveis por 73,9\% do total de mortes ocorridas no Brasil. Dentre todas as causas de DCNT, as doenças de origem cardiovascular, neoplásicas e de causas externas de morbidade e de mortalidade geralmente são as mais frequentes neste estudo (GUIMARÃES et al., 2015). O processo de envelhecimento e o aumento da expectativa de vida da população também são fatores preponderantes para o aumento dos índices de mortes por DCNT, visto que a indecência de determinadas doenças aumenta com a maior idade, principalmente aquelas relacionadas às doenças cardiovasculares, às neoplasias e às respiratórias. A prevalência de mortes em Criciúma foi da população idosa, cuja idade estava entre 70 e 79 anos, seguida da população com faixa etária acima dos 80 anos (CAMPOS; CERQUEIRA; NETO, 2011). Quanto ao gênero, a mortalidade masculina é sempre marcada por elevados índices de mortes, comparados aos índices de morte da população do sexo feminino, bem como é elevada em todas as faixas etárias e praticamente em todas as causas de óbitos. Em Criciúma, a prevalência se deu em óbitos masculinos, com 5.832 casos (LAURENTI; JORGE; GOTLIEB, 2005). Ao término do estudo na cidade de Criciúma, identificou-se que a maior causa de morte nesta cidade está relacionada às doenças do aparelho circulatório, seguida das doenças de causa neoplásica e das doenças do aparelho respiratório. A maior incidência se dá em pessoas do sexo masculino e em pessoas acima dos 70 anos de idade. Além disso, concluiu-se que estudos que descrevem o perfil de mortalidade de uma cidade ou região são imprescindíveis para o desenvolvimento de novas políticas ou repadronização das açóes já em desenvolvimento, a fim de garantir maior abrangência dos serviços de saúde na família ou na comunidade, de forma que possibilite a redução dos índices de mortes que poderiam ser evitadas e que aumentam desenfreadamente. 
Palavras-chave: Epidemiologia; Mortalidade; Sistemas de Informação.

\section{REFERÊNCIAS}

GUIMARÁES, R. M. et al. Diferenças regionais na transiçâo da mortalidade por doenças cardiovasculares no Brasil, 1980 a 2012. Revista Panamericana de Salud Pública [on-line], v.37, n.2, p.83-89, 2015.

IBGE. Censo Demográfico de Criciúma em 2010. Disponível em: <http:// www.cidades.ibge.gov.br/xtras/perfil.php?lang=\&codmun $=420460 \&$ search $=-$ santa-catarina|criciuma>. Acesso em: 29 jan. 2016.

LAURENTI, R.; JORGE, M. H. P. M.; GOTLIEB, S. L. D. Perfil epidemiológico da morbi-mortalidade masculina. Ciência e Saúde Coletiva, Rio de Janeiro, v.10, n.1, p.35-46, 2005.

OLIVEIRA-CAMPOS, M.; CERQUEIRA, M. B. R.; RODRIGUES NETO, J. F. Dinâmica populacional e o perfil de mortalidade no município de Montes Claros (MG). Ciência e Saúde Coletiva, Rio de Janeiro, v.16, n.1, p.13031310, 2011. 